\title{
Urban Land Expansion and Spatial Dynamics in Globalizing Shanghai
}

\section{Han Li ${ }^{1}$, Ye Hua Dennis Wei ${ }^{1,2, *}$ and Zhiji Huang ${ }^{3}$}

1 Department of Geography, University of Utah, Salt Lake City, UT 84112-9155, USA; E-Mail: han.li@geog.utah.edu

2 Key Research Institute of Yellow River Civilization and Sustainable Development \& Collaborative Innovation Center on Yellow River Civilization of Henan Province, Henan University, Kaifeng 475001, China

3 College of Urban and Environmental Sciences, Peking University, Beijing 100871, China; E-Mail: zjhuang@pku.edu.cn

* Author to whom correspondence should be addressed; E-Mail: wei@geog.utah.edu; Tel.: +1-801-585-0545; Fax: +1-801-585-8218.

External Editor: Marc A. Rosen

Received: 7 October 2014; in revised form: 18 November 2014 / Accepted: 24 November 2014 / Published: 3 December 2014

\begin{abstract}
Urban land expansion in China has attracted considerable scholarly attention. However, more work is needed to apply spatial modeling to understanding the mechanisms of urban growth from both institutional and physical perspectives. This paper analyzes urban expansion in Shanghai and its development zones (DZs). We find that, as nodes of global-local interface, the DZs are the most significant components of urban growth in Shanghai, and major spatial patterns of urban expansion in Shanghai are infilling and edge expansion. We apply logistic regression, geographically weighted logistic regression (GWLR) and spatial regime regression to investigate the determinants of urban land expansion including physical conditions, state policy and land development. Regressions reveal that, though the market has been an important driving force in urban growth, the state has played a predominant role through the implementation of urban planning and the establishment of DZs to fully capitalize on globalization. We also find that differences in urban growth dynamics exist between the areas inside and outside of the DZs. Finally, this paper discusses policies to promote sustainable development in Shanghai.
\end{abstract}


Keywords: economic transition; urbanization; urban land expansion; development zones; Shanghai; China

\section{Introduction}

Chinese cities have been experiencing drastic urban land expansion since the period of economic reform that began in 1978, in turn causing serious social justice, equitable development and environmental protection issues [1,2]. Shanghai, China's leading global city and the "dragon's head" of the Yangtze River Delta, has been undergoing significant urban growth since 1990, when the central government established the Pudong New Area. Between 1993 and 2009, the city's built-up area increased from $300 \mathrm{~km}^{2}$ to $886 \mathrm{~km}^{2}$, with a $6.5 \%$ annual growth rate [3]. The land development of Shanghai is the result of interactions between market and state, and global and local forces [4-8]. Given its massive urban population and land size, as well as its sensitivity to global change, a better understanding of urbanization and land expansion in Shanghai is critical to the development and sustainability of both Shanghai and China.

The existing studies of the process and mechanisms of urban growth in China are confined in the two perspectives, the institutional perspective and the neoclassical perspective, and both of them have weaknesses [2]. The institutional perspective has argued that urban growth in Chinese cities is shaped by the state and the market [2,9]. The scholars, from this perspective, have investigated the internal land use change of development zones (DZs) [10-12]. Other scholars from the neoclassical perspective have demonstrated that urban growth in China is influenced by accessibility and neighboring land use types $[6,13,14]$. Integration of these perspectives will provide a fuller understanding of urban growth in China. Spatial patterns of land expansion in urban China have also garnered much attention, especially from geographers [15-18]. Based on spatial analysis methods in a geographic information system (GIS) environment, they have identified three major patterns of urban land expansion in China: infilling, expansion, and leapfrog [19-21]. However, underlying forces shaping these patterns and their linkages to the powers of state and market are largely unexplored.

In this study, we assessed the extent of urban land expansion in Shanghai, including the Pudong New Area and the development zones, from 1991 to 2010. In particular, by applying a patch analysis method in GIS on the land use change images, we identified the spatial patterns of urban land expansion in Shanghai. We also applied global logistics regression, logistic spatial regime regression and geographically weighted logistic regression (GWLR) to investigate the interaction between the development of urban land and accessibility, state policy/planning and neighborhood land use to better understand the mechanisms of urban growth, and to quantify the interactions between state and market powers.

\section{Literature Review}

Studies on urban growth in China with the neoclassical perspective apply statistical, remote sensing and GIS techniques to investigate the relationships between urban growth, economic development, accessibility, and the neighborhood effects [6,13,16,22-25]. They find that economic growth [26], development of transportation systems [27], increase of tertiary industry and average salary [28] and rural-urban migration [29] are important driving forces of urban growth. While this line of research tends 
to emphasize accessibility and physical capital, they have also attempted to incorporate institutional factors into the analysis [2].

Scholars using the institutional perspective have examined the process of economic transition in China and its influence on local governance, the transfer of land use right, conversion of rural land use, and contradictions between different types of planning [30-32]. Since the 1990s, there has been an intense debate about whether the market or the state is more responsible for urban growth in China, because economic transformation is a gradual process in which the market system and the planning system coexist [4,5]. Some scholars argue that urban growth in Chinese cities is impacted by the triple transition of globalization, marketization, and decentralization [2,32]. They also analyze the process of administrative change and explain how these changes lead to urban growth [33-35]. Agents of planning and regulation implementation, local governance, as well as different components of central and local governments, have aroused extensive discussion [36-38].

The development zone fever is also an important factor contributing to urban growth in China [10,12,39]. Because DZs are established to attract foreign investment, foreign investment in its turn has become one of the most significant indicators influencing the spatial and structural transformation of urban China $[4,5,11]$. Some scholars have examined the relationship between land administration systems and the development of DZs [10], and others have focused on urban land use change inside DZs [12].

The decentralization of urban governance transfers control of urban development from the central government to local government [32]. Since the 1990s, metropolitan and district governments have gradually gained more administrative power in economic development, urban planning, and land management. Since 1992, the right of land use planning has been given to district and county governments, who are now responsible for preparing detailed development plans. However, this division of power between the municipal and district governments differs from place to place, causing dissimilarities in patterns and dynamics of urban growth across cities [4,32]. Scholars point out that state planning efforts, such as establishing DZs, play a significant role in the urban growth of Beijing [40], while others find that enterprises and foreign investments have become major driving forces of urban expansion in cities of the Pearl River Delta [27,38,41,42].

Different processes of urban expansion lead to dissimilar spatial patterns of urban growth. Empirical studies (e.g., [15,18,43-45]) find that diverse patterns across cities are due to dissimilar geographic and economic conditions. For example, in Chengdu, geographers find that the major pattern before 2000 is expansion, but after 2000, infilling and leapfrog become the major patterns of urban growth [16]. $\mathrm{Xu}$ et al. [17] have observed that this major pattern in Nanjing has transformed the city since 1988 from expansion to infilling and leapfrogging. The sprawl of Beijing is based on urban traffic loops of concentric circles [43], while Hangzhou and Wuhan have shown the typical polycentric expansion patterns $[18,44]$. We could conclude that there is not one simple pattern that works to describe development and expansion in all Chinese cities. Therefore, the analysis of urban growth patterns in Shanghai expands the body of literature, and demonstrates that patterns of urban growth indeed vary across Chinese cities.

To summarize, five areas need further investigation. First, despite the intense debate over whether the state or the market has greater influence on urban expansion in China, few studies have addressed this issue quantitatively. Second, there is a literature gap describing how urban growth drivers in Chinese cities vary across different institutional, geographic and economic conditions. Third, most studies are weak regarding underlying dynamics which shape these different spatial patterns of urban land expansion in 
China. Fourth, there is a dearth of literature concentrating on the site-decision of the DZs and the impact of DZs on urban growth in China. Finally, few studies specifically address the patterns and dynamics of Shanghai's expansion, and we still do not fully understand its urban growth patterns and driving forces.

\section{Data and Methodology}

\subsection{Study Area}

Shanghai is the largest city in China and had a registered population of nearly 18.4 million in 2008 and a total area of $6340.5 \mathrm{~km}^{2}$ [3] (Figure 1). From 1949 to 1978, Shanghai was the manufacturing center of China, and urban land use was concentrated in the west area of the Huangpu River. However, from 1979 to 1990, Shanghai had relatively low economic and urban growth rates, because special economic zones (SEZs) emerged as the new centers of foreign and domestic investments [12]. Since the early 1990s, the central government has granted the municipality greater power to attract foreign investment, which has resulted in an intense development of the city.

Figure 1. Study area.

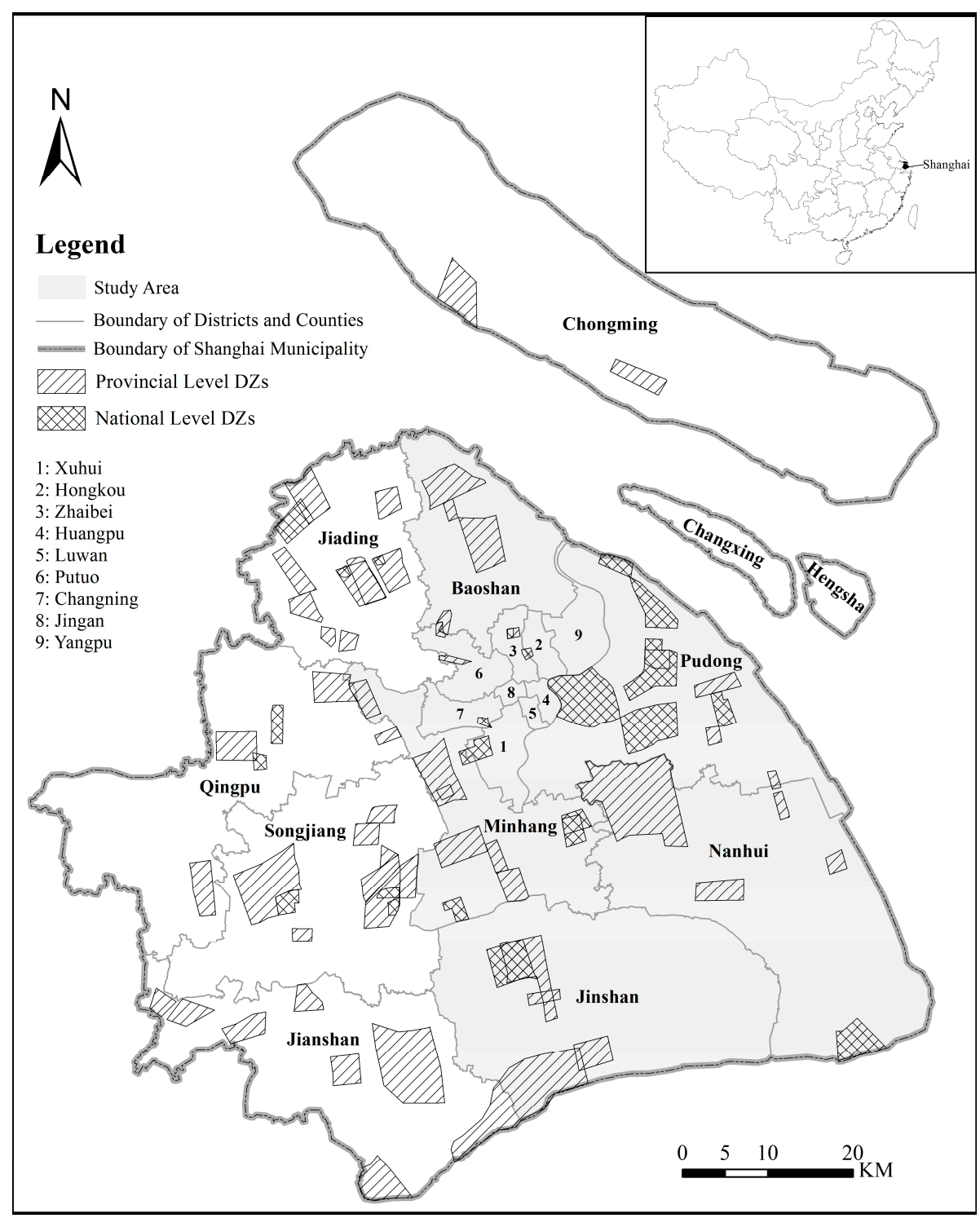


In order to meet the demands of accelerating economic growth and urbanization, urban space in Shanghai has been continuously expanded and restructured since the 1990s. In 1991, Shanghai was divided into 12 urban districts and 9 suburban counties (Table 1). In 2010, the number of districts increased to 19. In 2009, the Nanhui district became a part of the Pudong New Area. In this study, we kept the traditional boundaries of the Pudong District, because the effects of the policies in the Pudong New Area from 1991 to 2010 were still concentrated in the traditional Pudong District.

Table 1. Counties and districts of Shanghai in1991 and 2010.

\begin{tabular}{cll}
\hline Categories & \multicolumn{1}{c}{1991} & \multicolumn{1}{c}{2010} \\
\hline \multirow{2}{*}{ Districts } & $\begin{array}{l}\text { Huangpu, Nanhui, Luwan, Xuhui, Changning, Jing'an, } \\
\text { Putuo, Zhabei, Hongkou, Yangpu, Minhang, Baoshan }\end{array}$ & $\begin{array}{l}\text { Huangpu, Nanhui, Luwan, Xuhui, Changning, } \\
\text { Jing, Putuo, Zhabei, Hongkou, Yangpu, } \\
\text { Minhang, Baoshan, Pudong New Area (Nanhui), } \\
\text { Jiading, Jinshan, Songjiang, Qingpu, Fengxian }\end{array}$ \\
\hline \multirow{2}{*}{ Counties } & $\begin{array}{l}\text { Shanghai, Jiading, Chuanshan, Nanhui, Fengxian, } \\
\text { Songjiang, Jinshan, Qingpu, Chongming }\end{array}$ & Chongming \\
\hline
\end{tabular}

Source: [3].

Due to the availability of data and the fact that urban land expansion mainly took place in the east of the Huangpu River, we selected eastern Shanghai, including 13 districts, as our study area (Figure 1). The total size of our study area is $3031 \mathrm{~km}^{2}$, accounting for $47.8 \%$ of the total area of Shanghai municipality.

\subsection{Data and Remote Sensing}

The land use data employed in this study was derived from Landsat TM and SPOT remote sensing images in 1991 and 2010. A spatial overlay operation was utilized to extract the conversion land map between two classified images. The locations of the city center, ports, airports, subway stations and suburban centers were extracted from planning scheme maps of 2010 [46]. The data concerning roads and rail networks of Shanghai in 1999 were obtained from the Chinese Academy of Urban Planning and Design, and road networks were divided into two types: inter-city highways and local artery roads. The planning information was extracted from the land use planning map of 2000, while the data source for the geographic area of DZs was taken from a report issued by the Ministry of Land Resource.

In order to capture the land use maps of Shanghai in 1991 and 2010, two TM images and eight SPOT images were included in this analysis in total. The resolution of the TM images is $30 \mathrm{~m} \times 30 \mathrm{~m}$, while the resolution of SPOT is $10 \mathrm{~m} \times 10 \mathrm{~m}$. Since the SPOT image for 1991 just has one band, we acquired TM 5 images of Shanghai in 1991 to capture the color information, and to fuse the images of SPOT 2 and TM 5 and get a more precise classification result. Therefore, the final image of 1991 was the result of image fusion from two TM 5 images and four SPOT 2 images. The final image of 2010 was coming from the integration of four images of SPOT 5.

A supervised maximum likelihood classification was used to classify the geo-referenced images. Four types of land use were classified in this process: construction land, agriculture, water body and forest. However, based on the normalized difference vegetation index (NDVI) result, we found that the percentage of pixels with a NDVI value greater than 0.3 was fewer than $0.3 \%$, which implies that there is almost no forest in our study area. Thus, we combined the agricultural land and forest land together in this study. 
The overall accuracies of this classification process of 1991 and 2010 are $86.27 \%$ and $92.17 \%$, with Kappa coefficients 0.83 and 0.86 , respectively. The result of the classification was also corrected based on the land use survey map of 2010.

\subsection{Methods}

In the past decade, the quantitative method has been employed more commonly with the help of remote sensing technology. Most realistic large-scale applications need to consider the use of various data sources - such as historical land use records, urban land use maps and remote sensing images - to construct the most significant geographic features of urban development [6,8,13,18,24,47-49]. Similar to these previous studies, the model adopted in this study is based on the integration of remote sensing, GIS and spatial econometrics. We employed the remote sensing technique to get the land use maps from 1991 and 2010 in raster format. The spatial analyses, including the patch analysis, sampling process, the extraction of the value to the sampling points, are all based on the GIS techniques (ArcGIS). These spatial analyses aim to provide the independent and dependent variables and capture the distribution of the spatial patterns of Shanghai's urban expansion. The spatial econometric includes the global logistic regression, logistic spatial regime regression and GWLR. We applied the global logistic regression to investigate the general dynamics of urban growth in Shanghai. To further identify the different mechanism inside or outside the DZs, the logistic spatial regime and GWLR were employed. ArcGIS, R, along with ENVI provide the tools essential in this research.

\subsubsection{Patch Analysis and Sampling}

To identify the spatial patterns of urban land expansion in Shanghai, and to distinguish the different dynamics between Shanghai and other cities, we applied the patch analysis in the GIS environment to investigate the spatial growth types of the topology of urban growth in Shanghai. Based on the research of Camagni et al. [20] and Wilson et al. [21], we generalized urban growth patterns into three types: infilling, expansion and leapfrog. An infill growth is defined as the development of a small tract of land mostly surrounded by urban built-up land. An expansion is defined as an expansion of the existing urban built-up land patch. Leapfrog development refers to developed parcels that are converted from non-developed parcels outside of and unconnected with the existing urban built-up land. For the convenience of implementation, a simple quantitative method to distinguish the three growth types is proposed using the following Equation (1):

$$
S=L_{c} / P
$$

where $L_{c}$ is the length of the common boundary of a newly grown urban area and the pre-growth urban patches, and $P$ is the perimeter of this newly grown area. Urban growth type is identified as infilling when $S \geq 0.5$, expansion when $0<S<0.5$, and spontaneous growth when $S=0$ indicates no common boundary [17].

Replicating Luo and Wei [13] and Liao and Wei [38], we employed a combined systematic and random scheme for land use data sampling, to ensure that sampled land use data represents the study area systematically and provides enough information on land use change. From the land use conservation areas, we extracted 1,752 regular spatial points with 60 internal pixels, which captured the spatial variations 
of land use change. The same process was also applied to the non-urban land use areas in 1991. At this stage, 5146 points were extracted. In order to balance the logistic regression, we randomly selected the same number of unchanged points. There are 1752 observations that represent the change from non-construction land to construction land use, randomly distributed in the study area, where the observation number of unchanged points is 1752 . The regression has 3504 total observations. All these observations were chosen systematically in order to provide enough samples to build unbiased logistic regressions.

\subsubsection{Global Logistic Regression, Geographically Weighted Logistic Regression (GWLR) and Spatial} Regime Analysis

Aiming to explore the driving forces of urban growth in Shanghai, we applied the global logistic regression to capture the relationship between probability of land use change and the explanatory variables. Formally, the model logistic regression is that Equation (2):

$$
\ln [\text { ChangeProb } /(1-\text { ChangeProb })]=C+\beta X
$$

where $C$ is the constant parameter, and $\beta$ is the parameter of independent variable $X$.

In order to identify the unique coefficient of each sample point and avoid the heterogeneity of spatial effects, we applied geographically weighted regression (GWR) to capture the spatially varying relationship between probability of land use conversion and explanatory variables. The idea of GWR is to assign every spatial unit a regression point and create local regression equations for each spatial unit based on specified weighted strategies that normally use Kernel function [50]. Consequently, the GWR allows the parameters to be estimated locally and to take the form as Equations (3) and (4):

$$
Y i=\beta_{0}\left(u_{i}, v_{i}\right)+\sum_{k} \beta_{k}\left(u_{i}, v_{i}\right) X_{i k}+\varepsilon_{i} i=1 \ldots \ldots n
$$

The equation of GWLR follows:

$$
\ln \left[\text { ChangeProb }_{i} /\left(1-\text { ChangeProb }_{i}\right)\right]=C_{i}+\sum_{k} \beta_{k i} X_{k i}
$$

where $C_{i}$ is the constant parameter which is specific to location $i$ : $k i$ is the parameter of independent variable $X_{k}$ at location $i$. Basically, there are two methods which are usually employed to obtain weights: fixed and adaptive kernels. The results from fixed kernels will be influenced by the density of sample points, because the fixed kernel function applies an optimal spatial kernel over the space [50,51]. For instance, in the area where data are sparse, the local variations may be overestimated, and for the area where data are dense, this approach may underestimate the local variations. The adaptive kernel function guarantees a certain number of nearest neighbors as local samples, which will better represent the degree of spatial heterogeneity. In this study, by replicating Luo and Wei [13], we employed the adaptive kernel function, which is based on the Gaussian distance function in this study.

We applied the spatial regime model to distinguish the dynamics between urban growth inside development zones and outside development zones, and to explore the interactions between the powers of the state and the market. In Equation (5), the strategy of development zones provided two new samples, which allows coefficients to vary across two different regimes: a regime of points inside DZs $(A)$ and a regime of points outside DZs $(B)$, 


$$
\left[\begin{array}{l}
g r_{i, t A}^{*} \\
g r_{i, t B}^{*}
\end{array}\right]=\left[\begin{array}{cccc}
Y_{i, t-1 A}^{*} & X_{i, t-1 A}^{*} & 0 & 0 \\
0 & 0 & Y_{i, t-1 B}^{*} & X_{i, t-1 B}^{*}
\end{array}\right]\left[\begin{array}{c}
b_{A} \\
\varphi_{A} \\
b_{B} \\
\varphi_{B}
\end{array}\right]+\left[\begin{array}{l}
v_{i, t A} \\
v_{i, t B}
\end{array}\right]
$$

where the subscripts $A$ and $B$ indicate different regimes, $g r_{i, t A}^{*}$ and $g r_{i, t B}^{*}$ are $N \times 1$ column vectors with observations for land use change possibilities for spatial regimes $A$ and $B$, respectively. $Y_{i, t-1 A}^{*}, Y_{i, t-1 B}^{*}$ are $N \times 2$ matrices including the constant term and the log of initial land change possibilities of each regime. $X_{i, t-1 A}^{*}, X_{i, t-1 B}^{*}$ are the $N \times K$ matrices of observations on other explanatory variables for each regime, and $v_{i, t A}, v_{i, t B}$ are the $N \times 1$ vectors of error terms [52].

\subsection{Variables}

Following the work of Luo and Wei [13], we chose the probability of non-urban to urban land conversion from 1991 to 2010 as the dependent variable for the proposed logistic models, including global logistic regression, GWLR, and spatial regime regression, with values of 0 (no conversion) and 1 (with conversion). Based on the primary concerns of previous research [4,5], there are three types of explanatory factors applied in the land use model: the attributes of the market, the attributes of urban growth patterns, and the attributes of state powers (Table 2).

Table 2. Variables.

\begin{tabular}{ccc}
\hline Abbreviations & Description & Type \\
\hline \multicolumn{3}{c}{ Response variables } \\
\hline VC & Probability of land use conversion & Dummy \\
\hline \multicolumn{3}{c}{ Predictor variables } \\
\hline DLW & Distance to local artery roads & Continuous \\
DEA & Density of agriculture land & Continuous \\
DEC & Density of construction land & Continuous \\
DEW & Density of water body & Continuous \\
\hline \multicolumn{4}{c}{} \\
\hline DC & Urban Growth Patterns \\
DHPR & Distance to major city center & Continuous \\
DSC & Distance to the Huangpu River & Continuous \\
\multicolumn{4}{c}{ Distance to sub-administration centers } & Continuous \\
\hline VDZ & State \\
VP & Development zones \\
PD & Land use planning area & Dummy \\
DHW & Pudong district & Dummy \\
DRL & Distance to inter-city highway & Continuous \\
DAA & Distance to railways & Continuous \\
DPP & Distance to airports & Continuous \\
DSWS & Distance to ports & Continuous \\
& Distance to subway stations & Continuous \\
\hline
\end{tabular}

Market behaviors mostly reflect the profits of the development. Shanghai has been the most developed city in China since the 1900 s, so the local artery roads were mostly developed before 1991. In the study, the variable of the distance to local artery roads is employed to represent the control of location decision 
in urban growth by the market power. According to previous studies, some geographers have pointed out that neighborhood land use conditions have a significant effect on land use transition [33]. These neighborhood variables can represent the cost of urban land development. Generally, the cost of land conversion from water body to construction land is much higher than the cost of a similar process from agriculture land to construction land. Therefore, we considered three neighborhood variables in our model: density of agriculture land, density of construction land, and density of water body [48].

In order to understand the expansion pattern of Shanghai-individual-core, multi-core, and along the Huangpu River - we built three variables to capture this feature of Shanghai: distance to major city center, distance to the Huangpu River, and distance to sub-administration centers. The expectation was that, if the city follows an individual-core pattern, the variable of distance to the major city center should be negatively significant, and if the city follows the multi-core development pattern, the distance to sub-administration centers should be significantly negative. If Shanghai develops beside the Huangpu River, the variable of distance to Huangpu River should be negative [19].

The inter-city highways, subway stations, airports, sea ports and railways are integration mechanisms of the urban transportation system and the main projects of the local governments; thus, the distance to these objectives can be interpreted as the state power effects [13,33]. We also added policy variables in this land use model to assess whether or not the city is driven by the state policy and land use plan. The variables are dummy variables, in which 1 means the sample point belonging to the development zones, planning areas or the Pudong district, while 0 represents a sample point that is not located in the DZs, planning areas or Pudong district. The area of development zones includes both the national level DZs and provincial level DZs.

All distance variables are calculated from the sample points to nearby features by Euclidean distance in ArcMap. The neighborhood defined for the three density variables is average value of raster in a square with a side length of $100 \mathrm{~m}$, which is calculated from focal function in ArcGIS.

\section{Land Use Change and Spatial Patterns Analysis}

\subsection{Land Use Change in Shanghai}

To measure the magnitude and patterns of urban land use change in Shanghai, we compared the two classification results of remote sensing images, and found that, from 1991 to 2010, the construction land area of eastern Shanghai increased $378.48 \mathrm{~km}^{2}$, and the increase rate was $38.45 \%$ (Table 3 ). This expansion scale of urban land of Shanghai is higher than most other cities in China [6,38]. On the other hand, this whole study area also lost nearly $15 \%$ of agriculture land and $50 \%$ of its water body due to an extensive sea area being converted from sea to construction land to develop new modern ports and harbors. In Pudong, the similar process also can be found. The Pudong New Area had a 41\% increment of construction land, and the speed of losing agriculture land is higher than the average speed of the study area.

Spatially, in 1991, most areas of the center district were covered by construction land. By 2010, we found that most expansion was concentrated in the neighbor districts of the central area (Figure 2), such as Baoshan, Minhang and Pudong. Because the areas of these three districts are much larger than center districts, the range of land expansion is relatively extraordinary. Urban land expansions in Jinshan and 
Nanhui are spatially scattered, while some are concentrated in coastal areas. Urban land expansion in Pudong is quite dissimilar from other districts. In 1991, most urban land in Pudong was concentrated in the area sideways of the Huangpu River. In 2010, urban land almost covered this entire district. We also found some significant agglomeration phenomenon in this process, which can be explained by the rise of development zones established by state policy and urban planning.

Table 3. Land use change in Eastern Shanghai and Pudong.

\begin{tabular}{|c|c|c|c|c|}
\hline \multirow{2}{*}{ Land Use Type } & \multicolumn{4}{|c|}{ Eastern Shanghai } \\
\hline & $1991\left(\mathrm{~km}^{2}\right)$ & $2010\left(\mathrm{~km}^{2}\right)$ & Change $\left(\mathrm{km}^{2}\right)$ & $\%$ of Change \\
\hline Construction & 984.45 & 1362.93 & 378.48 & 38.45 \\
\hline Water Body & 174.85 & 88.86 & -85.99 & -49.18 \\
\hline Agriculture & 1871.35 & 1578.85 & -292.49 & -15.63 \\
\hline \multirow{2}{*}{ Land Use Type } & \multicolumn{4}{|c|}{ Pudong } \\
\hline & $1991\left(\mathrm{~km}^{2}\right)$ & $2010\left(\mathrm{~km}^{2}\right)$ & Change $\left(\mathrm{km}^{2}\right)$ & $\%$ of Change \\
\hline Construction & 208.07 & 293.36 & 85.283 & 40.99 \\
\hline Water Body & 49.43 & 32.23 & -17.21 & -34.79 \\
\hline Agriculture & 302.68 & 234.59 & -68.08 & -22.49 \\
\hline
\end{tabular}

Figure 2. Land use map of eastern Shanghai in 1991 and 2010.
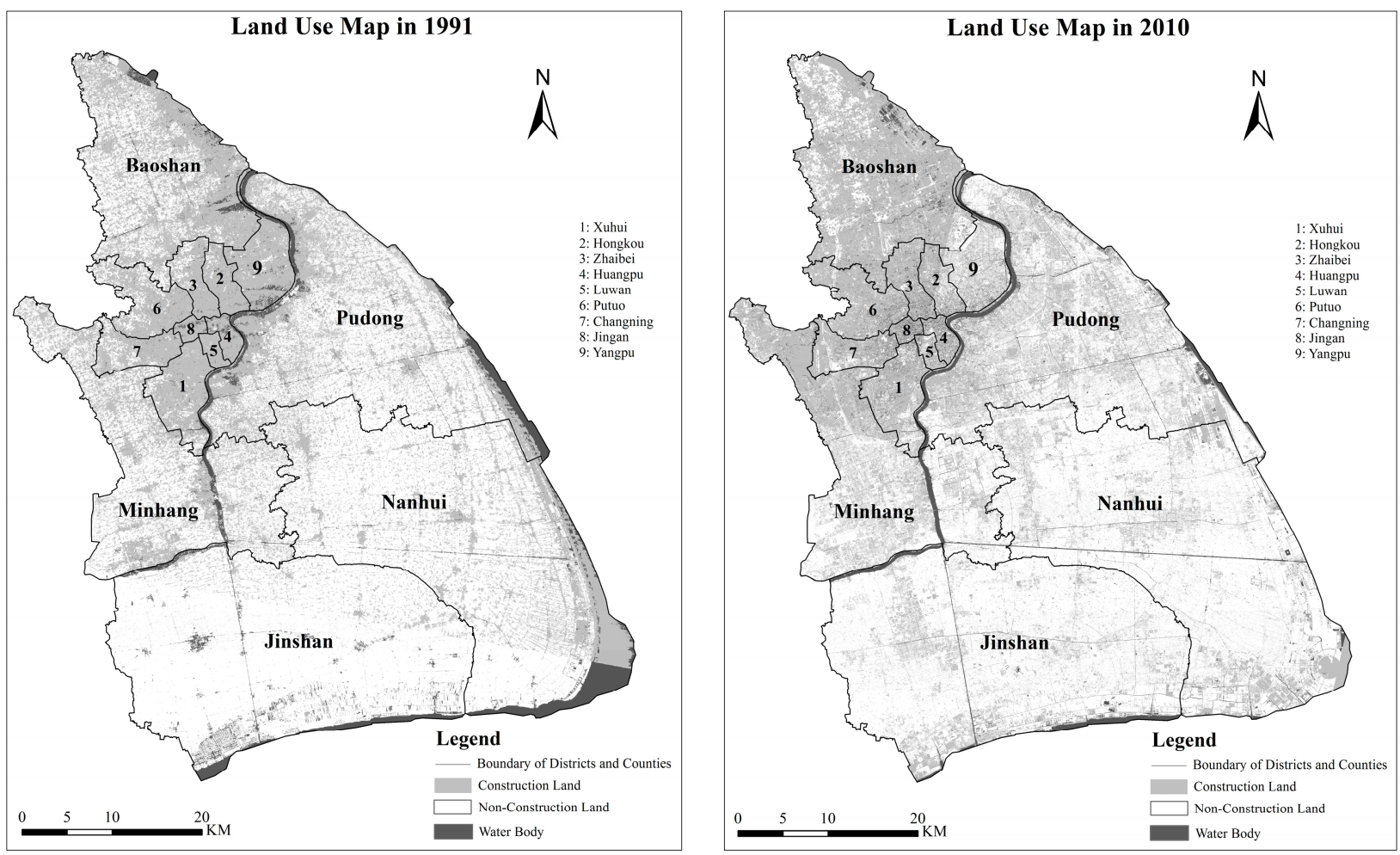

In order to understand how the state policies and municipal government influence urban land expansion in Shanghai, we evaluated the land use change of the DZs in our study area separately [11]. In 2006, there were 12 national level DZs and 26 provincial level DZs in Shanghai. The total area of national DZs and provincial DZs were $209.02 \mathrm{~km}^{2}$ and $431.85 \mathrm{~km}^{2}$, respectively. In this study area, there were $180.71 \mathrm{~km}^{2}$ and $332.26 \mathrm{~km}^{2}$ national and provincial development zones, accounting for $86.45 \%$ and $76.94 \%$ of DZs' area in the Shanghai municipality, respectively. 
There is a more than $820 \%$ increase of construction land use in national level DZs, which is much higher than the average increase ratio of this study area (Table 4). In the national level DZs, more than $92 \%$ of water areas convert to construction land, because there are several significant coastal harbors built in these DZs. The increase of construction land in provincial level DZs is $102.20 \%$, which is much lower than the rate in national level DZs, but still higher than the average level of this area. The total amount increase of construction land in DZs from 1991 to 2010 is $190.06 \mathrm{~km}^{2}$, accounting for more than $50 \%$ of construction land increase of this study area. Thus, we suggested that the development of DZs plays the most significant role in urban development in Shanghai, and the development of national DZs occurs more quickly than provincial DZs because the hierarchy of state policy still plays a significant role in Shanghai's development [4].

Table 4. Land use change in DZs.

\begin{tabular}{cccccc}
\hline Land Use Type & \multicolumn{2}{c}{ Amount $\left.\mathbf{( k m}^{\mathbf{2}}\right)$} & \multicolumn{4}{c}{ Percentage of Total Change (\%) } \\
\hline National DZs & 1991 & 2010 & 1991 & 2010 & $1991-2010$ \\
Construction Land & 12.09 & 111.71 & 6.69 & 61.81 & 823.37 \\
Non-Construction & 64.46 & 61.69 & 35.67 & 34.13 & -4.31 \\
Water Body & 104.15 & 7.32 & 57.63 & 4.05 & -92.97 \\
\hline Total & 180.71 & 180.71 & 100.00 & 100.00 & 0 \\
\hline Provincial DZs & 1991 & 2010 & 1991 & 2010 & $1991-2010$ \\
Construction Land & 88.44 & 178.89 & 26.62 & 53.84 & 102.27 \\
Non-Construction & 234.44 & 150.66 & 70.56 & 45.34 & -35.74 \\
Water Body & 9.38 & 2.72 & 2.82 & 0.82 & -71.05 \\
\hline Total & 332.26 & 332.26 & 100.00 & 100.00 & 0 \\
\hline
\end{tabular}

\subsection{Spatial Patterns of Urban Growth in Shanghai}

Shanghai also has its unique spatial pattern in the expansion process. According to the patch analysis, three types of urban growth can be identified quantitatively: infilling, expansion and leapfrog. In eastern Shanghai and Pudong, infilling and expansion comprise the majority at more than $88 \%$ and $92 \%$ of the conversion of construction land use, respectively (Figure 3). Comparing these statistics with previous studies, we found that in different cities with diverse economic and geographic conditions, the spatial patterns also vary. For example, in the polycentric development cities such as Nanjing and Hangzhou, leapfrog and expansion are the major patterns $[8,17]$, while in the town-based development cities such as Dongguan, leapfrog is the leading pattern of urban growth [38].

Spatial distribution of these patterns in our study area can be found in Figure 4. We found that, in the neighbor districts of urban center area, the pattern is dominated by infilling. However, leapfrog mainly dominates some sub-administration centers such as Nanhui and Jinshan, and some coastal areas. In 1991, the roads and some other basic infrastructures were already built in these areas, and development in the next 19 years has just filled the construction land in this network of roads and infrastructures. When the central and municipal authorities make site decisions for the DZs, the maturity of infrastructure conditions is one of the significant criteria. Consequently, the development patterns of DZs in Shanghai are expansion and infilling. The leapfrog parcels represent some land developments of the sub-districts, which are driven by the local government and non-state-owned enterprises. 
To examine the mismatches between real development and planning design of land use, we compared the patterns map below (Figure 4) with the land use planning map from 2000 [46], and found that they matched perfectly. There is not much leapfrogging of industrial land and residential land use in Nanhui and Jinshan in the land use map, and all the planned construction land uses are defined and ranged by the roads. Based on the result of patch analysis, it is suggested that the urban development of Shanghai is under the strict control of urban planning and land use planning.

Figure 3. Percentage of spatial patterns in urban land expansion.
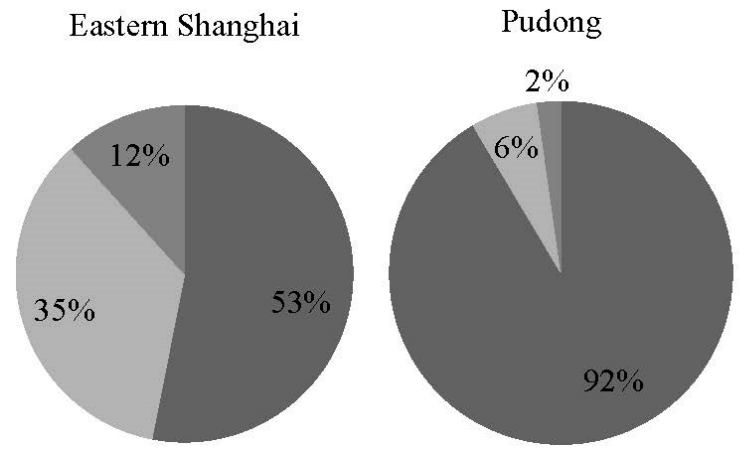

Infilling

Expansion

Leapfrog

Figure 4. Distribution of Spatial Patterns of Construction Land Expansion in Eastern Shanghai.

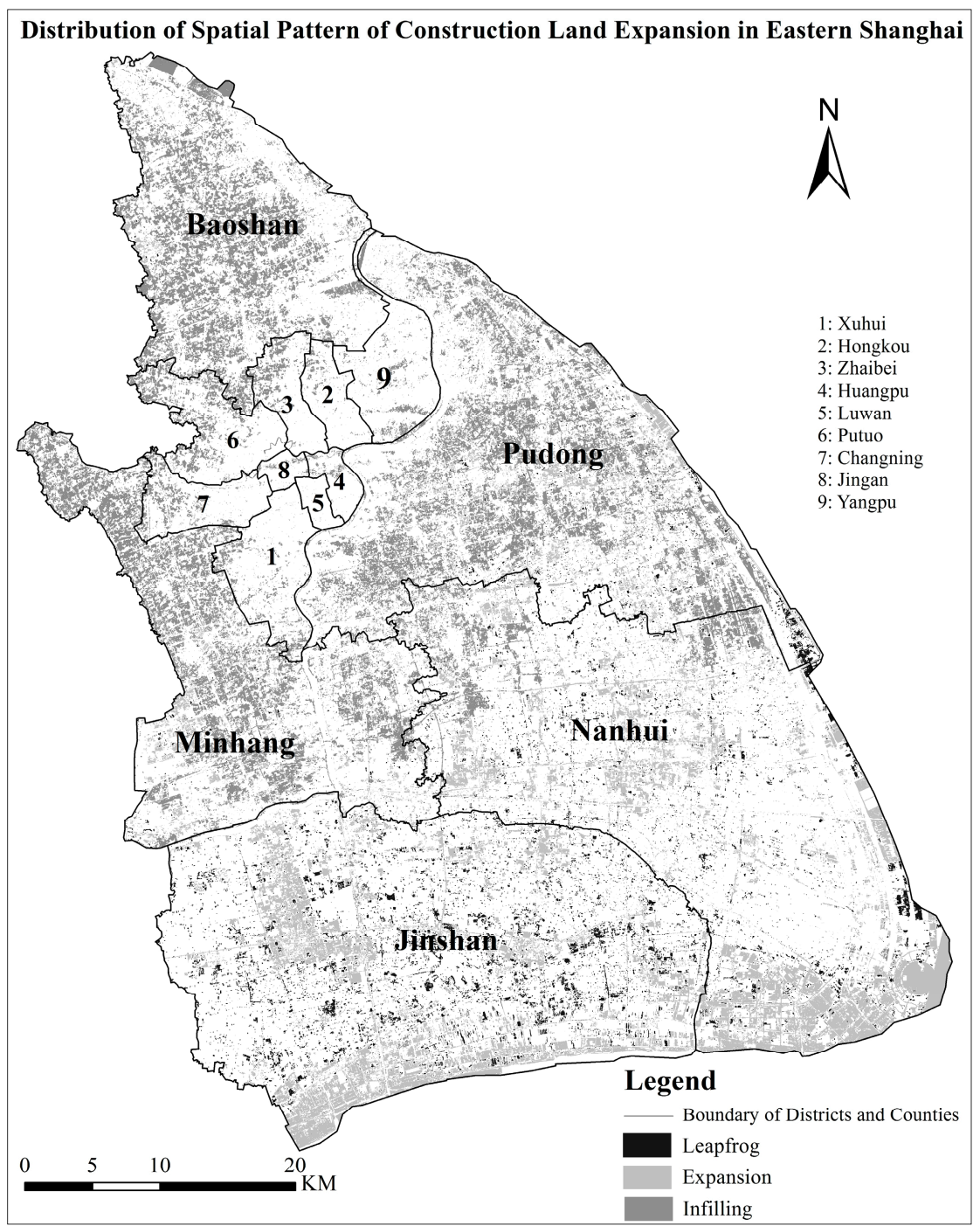




\section{Determinants of Urban Growth in Shanghai}

To avoid the multi-collearity problem of the afterwards regression analyses, we tested the variance inflation factor (VIF) of all explanatory variables, and found that all the results of VIF are smaller than 2, thus indicating that no pair of variables has a significant linear correlation. Table 5 represents the results of the global logistic regression and GWLR. The receiver-operating characteristic (ROC) results are larger than 0.8 for all the models, which are located in the convinced interval (Table 5).

First, from the state power perspective (Table 5), we found that the distance to railway (DRL) has the strongest negative effect on land conversion probability, which is different from the result of Nanjing and Wuhan $[13,48]$. The distance to highways (DHW) and the distance to subway stations (DSWS) are insignificant, which can be interpreted as meaning that our study area is not a traditional transportation hub. The coefficients of distances to airports and ports (DAA and DPP) are also significantly positive, which represents the urban growth that occurs in the area further distant from airports and ports, in order to avoid pollutants such as noise.

Table 5. Global logistic regression and GWLR result.

\begin{tabular}{cccc}
\hline Area & Global Logistic & \multicolumn{2}{c}{ GWLR } \\
\hline Variables & Coefficient & Mean Coefficient & Positive \\
\hline \multicolumn{4}{c}{ Market } \\
\hline DLW & $-0.174 * * *$ & -0.219 & $22.17 \%$ \\
DEA & 0.399 & 2.984 & $62.96 \%$ \\
DEC & $-3.605 * *$ & -0.905 & $25.43 \%$ \\
DEW & 1.069 & 3.391 & $67.29 \%$ \\
\hline \multicolumn{4}{c}{ Urban growth pattern } \\
\hline DC & $-0.096 * *$ & -0.076 & $0.00 \%$ \\
DSC & $0.015 *$ & 0.012 & $86.47 \%$ \\
DHPR & $0.092 * * *$ & 0.092 & $100.00 \%$ \\
\hline \multicolumn{4}{c}{ State } \\
\hline VDZ & $0.922 * * *$ & 0.903 & Global Variable \\
VP & $0.669 * *$ & 0.661 & Global Variable \\
PD & $0.234 * *$ & 0.304 & Global Variable \\
DHW & 0.014 & 0.020 & $62.93 \%$ \\
DRL & $-0.042 * *$ & -0.065 & $0.00 \%$ \\
DAA & $0.022 * *$ & 0.013 & $72.06 \%$ \\
DPP & $0.014 * *$ & 0.016 & $90.04 \%$ \\
DSWS & -0.003 & -0.021 & $31.28 \%$ \\
\hline Constant & 1.354 & Assessment & 3504 \\
AIC & 3859.4 & -0.993 & 0.834 \\
Observations & 3504 & AIC & \\
ROC & 0.802 & Observations & \\
Pseudo R & 0.26 & & 3754.4 \\
\hline
\end{tabular}

Note: $* * *$ Indicate significance at 0.01 Level. $* *$ Indicate significance at 0.05 Level. * Indicate significance at 0.1 Level. 
The coefficients of DZs, planning areas and Pudong (VDZ, VP and PD) should be highlighted, because these variables are the most significant indicators in demonstrating how state power influences the urban development in Shanghai. The coefficient of VDZ is 0.922 , which is very significantly high as a dummy variable in logistic regression. The parameter estimate of VP is also significantly high. The coefficient of PD is lower than VDZ and VP, but it is still very high. The results of these variables prove that our hypothesis, that state policy and planning, are the major driving forces of urban growth in Shanghai, which also matches with the conclusion of $\mathrm{Wu}$ [4], pointing to the strong government regulation in Shanghai.

Second, from the market power perspective, distance to local artery roads (DLW) is the most significant variable, which is similar to the findings of previous studies [13,33]. The rise of proximity to city streets in land development is important in many large cities of China, and the coefficients of density of agriculture land (DEA) and water (DEW) are both positive but not significant. These results imply that the potentiality and restriction are not important in Shanghai's development, because the development of DZs is decided by the local and central government, and attracts a huge amount of investment, which devaluates the expense of the land conversion. Moreover, because Shanghai already had a stable large scale of urban core in 1991, the land use expansion in this urban core should be relatively rare. In the study of Nanjing and Wuhan, density of agriculture land is significantly positive, thus representing the potentiality of urban growth. Water area is one of the significant restrictions of urban growth.

Third, the local government of Shanghai proposed polycentric development as one of the major strategies of urban growth in its urban master plan in 1999 [46]. However, our results reveal that expansion from just one city center is the principal spatial pattern of urban growth in Shanghai. For instance, among the urban growth pattern variables, distance to major city center (DC) has the strongest significant negative impact on the urban development, while the distance to sub-administration centers (DSC) has positive influence on the urban growth in this study area. These two variables imply that the pattern of urban development of this study area is individual-core, which matches the previous institutional studies [4,5]. The parameter of distance to the Huangpu River (DHPR) is significantly positive, which rejects the idea that Shanghai's development is along the Huangpu River.

We employed the GWLR to find out how spatial variations affect urban growth determinants. The results prove that all parameters vary across the study area with generally regular spatial patterns. Among the variables of the market, the most significant impact on urban growth is distance to roads, with 22.17 positive percentages. In the different areas of our study, the neighborhood land use also performs the different impacts on the urban growth, because the positive and negative percentages are almost equal in this category, which implies that there are huge spatial variations in these variables' influence on urban growth in our study area.

Moreover, among the variables of state power, DRL has the lowest positive percentage of coefficients $(0 \%)$, which is consistent with the result of global logistic regression. Other variables in the state category, such as DAA, DHW, and DPP, have different impacts on urban growth based on the spatial differences. Due to the introduction of the GWLR in this study, there are some decreases in coefficients of VDZ, VP and PD. Furthermore, there is not a fixed pattern of influences on the distances to sub-administration centers and Huangpu River. We could suggest that urban growth in Shanghai is relative to the distance to the major city center, in which $86.47 \%$ of coefficients are negative. Overall, regression models effectively explain the determinants of probability of Shanghai from a global view, and prove that urban land expansion is driven by both the state and market forces. 


\section{Determinants Change in Development Zones? Evidence from Spatial Regime and GWLR}

We employed spatial regime regression and GWLR to investigate the different dynamics across the DZs (Table 6). For the sample points inside DZs, we found that they are more sensitive to the variables of state infrastructure powers, such as distance to subway stations, highways, railways, ports and airports, which match the infrastructure requirements of establishing a DZ (Table 6). The urban growth pattern variables indicate that the preferences of location choices of DZs are concentrated in the suburb, which is far away from the major city center and close to the sub-administration centers. However, the urban growths in DZs are less sensitive to the variables of market power, in which only the DEC is marginally positive.

Table 6. Results of Spatial Regime and GWLR for DZs.

\begin{tabular}{ccccccc}
\hline Model & \multicolumn{2}{c}{ Spatial Regime } & \multicolumn{3}{c}{ GWLR } \\
\hline Categories & In & Out & \multicolumn{2}{c}{ Out } \\
\hline Variables & Coefficient & Coefficient & Mean & Positive & Mean & Positive \\
\hline \multicolumn{7}{c}{ Market } \\
\hline DLW & 0.168 & $-0.215 * *$ & 0.087 & $95.82 \%$ & -0.292 & $4.76 \%$ \\
DEA & 1.411 & 0.518 & 8.807 & $94.18 \%$ & 1.607 & $55.56 \%$ \\
DEC & $2.87 *$ & $-3.344 * *$ & 3.901 & $63.58 \%$ & -2.043 & $16.40 \%$ \\
DEW & 0.355 & 1.385 & 7.983 & $87.46 \%$ & 2.305 & $62.50 \%$ \\
\hline \multicolumn{7}{c}{ Urban growth pattern } \\
\hline DC & $0.008 *$ & $-0.099 * * *$ & -0.035 & $0.00 \%$ & -0.086 & $0.00 \%$ \\
DSC & -0.009 & $0.014 *$ & 0.011 & $82.54 \%$ & 0.013 & $87.37 \%$ \\
DHPR & 0.011 & $0.079 * *$ & 0.074 & $100.00 \%$ & 0.096 & $100.00 \%$ \\
\hline \multicolumn{7}{c}{ State } \\
\hline DHW & $-0.003 *$ & $0.043 * * *$ & -0.002 & $37.01 \%$ & 0.0252 & $69.38 \%$ \\
DRL & $-0.071 * * *$ & $-0.036 * *$ & -0.079 & $0.00 \%$ & -0.062 & $0.00 \%$ \\
DAA & $-0.009 *$ & 0.009 & 0.008 & $77.76 \%$ & 0.015 & $70.72 \%$ \\
DPP & $-0.016 *$ & 0.006 & 0.010 & $78.66 \%$ & 0.018 & $92.80 \%$ \\
DSWS & $-0.079 * *$ & 0.015 & -0.058 & $0.00 \%$ & -0.012 & $38.66 \%$ \\
Constant & 1.871 & -6.481 & $30.60 \%$ & 0.306 & $70.41 \%$ \\
\hline AIC & 3866.8 & \multicolumn{7}{c}{3754.4} \\
\hline
\end{tabular}

Note: $* * *$ Indicate significance at 0.01 Level. $* *$ Indicate significance at 0.05 Level. * Indicate significance at 0.1 Level.

For the sample points outside of the DZs, we found that there is an apparent dissimilarity from the points inside of the DZs. The urban growth outside of the DZs is determined by the market powers. In both results of spatial regime and GWLR, we found that the DLW has a significantly negative influence on the urban land expansion in Shanghai. The variables DEA and DEC, which represent the cost of land conversion, are more consistent with the results of Nanjing and Dongguan [13,38]. This category of land development is more sensitive for the distance of city center. However, in the variables representing state power, only the coefficient of DRL is significantly negative and the DHW has a positive influence, which is opposite of the result from points inside of the DZs. 
Therefore, it is important to point out that the dynamics of urban growth vary across DZs. The urban expansion outside the DZs is influenced more significantly by market variables, while the urban development inside of DZs is more likely to be controlled by the state variables.

Based on the parameter results for all the sample points, we developed three parameter surfaces to reveal the spatial variations of urban growth patterns in Shanghai. The method we employed is the inverse distance weighted (IDW) interpolation algorithm. IDW assumes that the surface is being driven by the local variation, which can be measured by the neighbor values [13], and hence is an applicable approach in this research. Figure 5 presents the parameter surface of DHW, DSWS and DLW with $100 \mathrm{~m}^{2}$ cell size.

From Figure 5, one can see that DHW and DSWS have more negative effects on the land development in the development zones than the outside area. On the other hand, DLW has a more negative influence on the land development outside of the development zones, which is opposite to the DHW and DSWS. As DLW represents the market power, and the DHW and DSWS represent the state power, Figure 5 describes the spatial distribution of the influences from these two forces on urban growth. It is clear that the influences of state power concentrate in the DZs, while the influences from market decision are primarily located outside of the DZs.

Figure 5. GWLR Parameter Surfaces of DHW, DSWS and DLW.

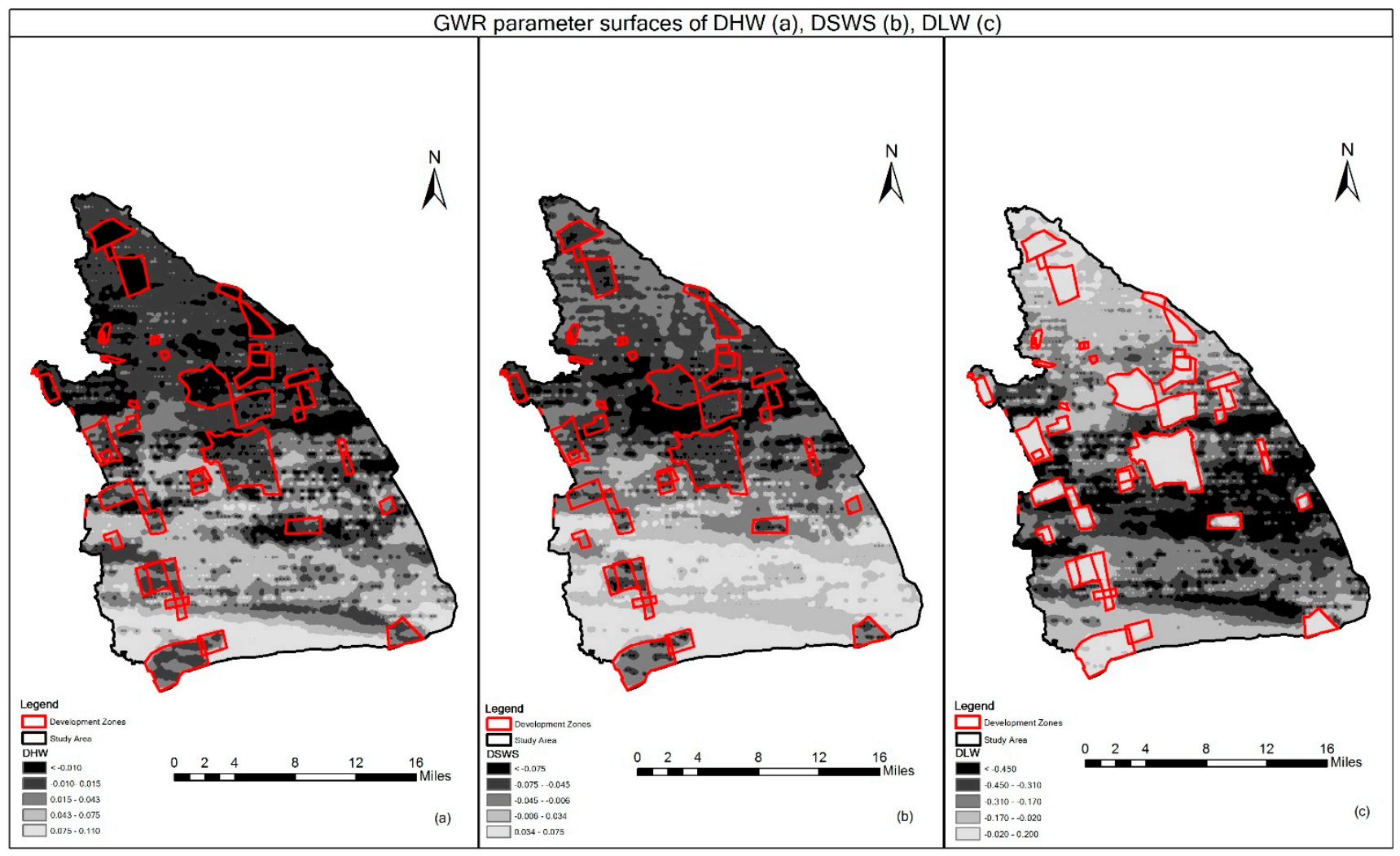

\section{Conclusions}

As China modernizes and urbanizes, spatial patterns and determinants of urban growth in large cities have become a focus of research on land use change. China's urban growth is influenced by the economic transition in China, and some scholars study mechanisms of urban expansion from an institutional 
perspective, and point out that state and market are the primary driving forces [4,5,53]. Moreover, since the 1990s, supply-driven land development has been a major feature of Chinese cities [54], which introduced spontaneous unregulated land conversion. Although the control of land has been decentralized to district governments, land leasing in Shanghai is still under strict control of the municipal government. Thus, urban expansion in Shanghai is being driven by local planning and state policy, such as the development of DZs. However, there are few quantitative results to support these findings and more rigorous analyses are needed to quantify the mechanisms. Conversely, other scholars have attempted to analyze urban growth in China based on physical components, such as accessibility and neighborhood land use conditions, and they tend to deemphasize explaining urban growth patterns from an institutional perspective.

In order to investigate urban growth in Shanghai, this study analyzes spatial patterns and determinants of urban growth by patch analysis and logistic regressions. We found that major patterns of urban growth are infilling and expansion. For development zones, the increase of construction land use is influenced by administrative hierarchy. The analysis of determinants of urban growth also proves that Shanghai is single-core based development, and that both state and market play a significant role in urban growth. The spatial regime regression proves that the dynamics vary across DZs. Thus, considering urban growth as a comprehensive phenomenon, urban expansion in Shanghai is not only affected by the penetration of foreign direct investments and multinational corporations, but also driven by local planning and state policy $[4,5]$.

The findings have profound policy implications for land use planning. The analysis suggests that there is still a significant government involvement in Shanghai's development. Urban land development in Shanghai is massive without considering sustainability of economic development and environment protection. Furthermore, differences between mechanisms of urban growth for large Chinese cities also suggest that land use policies are fragmented. The gap between plan making and implementation is still a problem with urban growth. Further attention should be paid to the understanding of the extent and likely consequences of urban expansion under the dualism of plan and market. Current studies within GIS methods are mainly considering the physical dynamics of urban growth, and to show the whole picture of mechanisms of urban land expansion in Chinese cities, more efforts should be made to incorporate socioeconomic processes.

\section{Acknowledgments}

We would like to acknowledge the funding of the National Natural Science Foundation of China (41329001; 41430637) and Lincoln Institute of Land Policy (CYW012213).

\section{Author Contributions}

Han Li analyzed the data, and Han Li and Ye Hua Dennis Wei wrote the paper. All authors contributed to data collection and mythological development, and have read and approved the final manuscript.

\section{Conflicts of Interest}

The authors declare no conflict of interest. 


\section{References}

1. Bai, X.; Shi, P.; Liu, Y. Realizing China's urban dream. Nat. Comments 2014, 509, 158-160.

2. Wei, Y.H.D.; Ye, X. Urbanization, urban land expansion and environmental change in China. Stoch. Environ. Res. Risk Assess. 2014, 28, 757-765.

3. SSB (Shanghai Statistical Bureau). Shanghai Statistical Yearbook; China Statistical Press: Beijing, China, 1975-2011.

4. Wu, F. The Global and Local Dimensions of Place-making: Remaking Shanghai as a World City. Urban Stud. 2000, 37, 1359-1377.

5. Timberlake, M.; Wei, Y.H.D.; Ma, X.; Hao, J. Global cities with Chinese characteristics. Cities 2014, 41, 162-170.

6. Han, J.; Hayashi, Y.; Cao, J. Evaluating land-use change in rapidly urbanizing China: Case study of Shanghai. J. Urban Plan. Dev. 2009, 135, 166-171.

7. Zhang, H.; Zhou, L.G.; Chen, M.N.; Ma, W.C. Land use dynamics of the fast-growing Shanghai Metropolis, China (1979-2008) and its implications for land use and urban planning policy. Sensors 2011, 11, 1794-1809.

8. Yue, W.; Fan, P.; Wei, Y.H.D.; Qi, J. Economic development, urban expansion, and sustainable development in Shanghai. Stoch. Environ. Res. Risk Assess. 2014, 28, 783-799.

9. Lin, G.C.S.; Wei, Y.H.D. China's restless urban landscapes 1: New challenges for theoretical reconstruction. Environ. Plan. A 2002, 34, 1535-1544.

10. Cartier, C. "Zone fever", the arable land debate, and real estate speculation: China's evolving land use regime and its geographical contradictions. J. Contemp. China 2001, 10, 445-469.

11. Wei, Y.H.D.; Leung, C.K. Development zones, foreign investment, and global city formation in Shanghai. Growth Chang. 2005, 36, 16-40.

12. Wei, Y.H.D.; Leung, C.K.; Luo, J. Globalizing Shanghai: Foreign investment and urban restructuring. Habitat Int. 2006, 30, 231-244.

13. Luo, J.; Wei, Y.H.D. Modeling spatial variations of urban growth patterns in Chinese cities: The case of Nanjing. Landsc. Urban Plan. 2009, 91, 51-64.

14. Schneider, A.; Mertes, C.M. Expansion and growth in Chinese cities, 1978-2010. Environ. Res. Lett. 2014, 9, doi:10.1088/1748-9326/9/2/024008.

15. Liu, J.; Liu, M.; Zhuang, D.; Zhang, Z.; Deng, X. Study on spatial pattern of land-use change in China during 1995-2000. Sci. China Ser. D Earth Sci. 2003, 46, 373-384.

16. Schneider, A.; Seto, K.C.; Webster, D.R. Urban growth in Chengdu, Western China: Application of remote sensing to assess planning and policy outcomes. Environ. Plan. B 2005, 32, 323-345.

17. Xu, C.; Liu, M.; Zhang, C.; An, S.; Yu, W.; Chen, J. The spatiotemporal dynamics of rapid urban growth in the Nanjing metropolitan region of China. Landsc. Ecol. 2007, 22, 925-937.

18. Liu, Y.; Yue, W.; Fan, P. Spatial determinants of urban land conversion in large Chinese cities: A case of Hangzhou. Environ. Plan. B 2011, 38, 706-725.

19. Forman, R.T.T. Land Mosaics: The Ecology of Landscapes and Regions; Cambridge University Press: Cambridge, UK, 1995.

20. Camagni, R.; Gibelli, M.C.; Rigamonti, P. Urban mobility and urban form: The social and environmental costs of different patterns of urban expansion. Ecol. Econ. 2002, 40, 199-216. 
21. Wilson, E.H.; Hurd, J.D.; Civco, D.L.; Prisloe, M.P.; Arnold, C. Development of a geospatial model to quantify, describe and map urban growth. Remote Sens. Environ. 2003, 86, 275-285.

22. Liu, H.; Zhou, Q. Developing urban growth predictions from spatial indicators based on multi-temporal images. Comput. Environ. Urban Syst. 2005, 29, 580-594.

23. Tan, M.; Li, X.; Xie, H.; Lu, C. Urban land expansion and arable land loss in China-a case study of Beijng-Tianjing-Hebei Region. Land Use Policy 2005, 22, 187-196.

24. Deng, X.; Huang, J.; Rozelle, S.; Uchida, E. Cultivated land conversion and potential agricultural productivity in China. Land Use Policy 2006, 23, 372-384.

25. Deng, X.; Huang, J.; Rozelle, S.; Uchida, E. Growth, population and industrialization, and urban land expansion in China. J. Urban Econ. 2008, 63, 96-115.

26. Tian, G.; Jiang, J.; Yang, Z.; Zhang, Y. The urban growth, size distribution and spatio-temporal dynamic pattern of the Yangtze River Delta megalopolis region, China. Ecol. Model. 2011, 222, 865-878.

27. Ma, Y.; Xu, R. Remote sensing monitoring and driving force analysis of urban expansion in Guangzhou City, China. Habitat Int. 2010, 34, 228-235.

28. Ding, C.; Lichtenberg, E. Land and urban economic growth in China. J. Reg. Sci. 2011, 51, 299-317.

29. Wang, L.; Li, C.; Ying, Q.; Cheng, X.; Wang, X.; Li, X.; Gong, P. China's urban expansion from 1990 to 2010 determined with satellite remote sensing. Chin. Sci. Bull. 2012, 57, 2802-2812.

30. Lin, G.C.S.; Ho, S.P. China's land resources and land-use change: Insights from the 1996 land survey. Land Use Policy 2003, 20, 87-107.

31. Yang, Y.R.; Wang, H.K. Dilemmas of local government under the development zone fever in China: A case study of the Suzhou Region. Urban Stud. 2008, 45, 1037-1054.

32. Wei, Y.H.D. Restructuring for growth in urban China: Transitional institutions, urban development, and spatial transformation. Habitat Int. 2012, 36, 396-405.

33. Wu, F.; Yeh, A.G.O. Changing spatial distribution and determinants of land development in Chinese cities in the transition from a centrally planned economy to a socialist market economy: A case study of Guangzhou. Urban Stud. 1997, 34, 1851-1879.

34. Xu, Z.; Zhu, N. Urban growth determinants in China. Chin. Econ. 2008, 41, 7-35.

35. Xu, J.; Yeh, A.G.O.; Wu, F. Land commodification: New land development and politics in China since the late 1990s. Int. J. Urban Reg. Res. 2009, 33, 890-913.

36. Ho, S.P.S.; Lin, G.C.S. Non-agricultural land use in post-reform China. China Q. 2004, 179, 758-781.

37. Ma, L.J.C. Urban administrative restructuring, changing scale relations and local economics development in China. Polit. Geogr. 2005, 24, 477-497.

38. Liao, F.H.F.; Wei, Y.H.D. Modeling determinants of urban growth in Dongguan, China: A spatial logistic approach. Stoch. Environ. Res. Risk Assess. 2014, 28, 801-816.

39. Deng, F.F.; Huang, Y. Uneven land reform and urban sprawl in China: The case of Beijing. Prog. Plan. 2004, 61, 211-236.

40. Ping, Y.C. Explaining land use change in a Guangdong county: The supply side of the story. China $Q$. 2011, 207, 626-648.

41. Seto, K.C.; Kaufman, R.K. Modeling the drivers of urban land use change in the Pearl River Delta, China. Land Econ. 2003, 79, 106-121. 
42. Fan, F.; Wang, Y.; Qiu, M.; Wang, Z. Evaluating the Temporal and Spatial Urban Expansion Patterns of Guangzhou from 1979 to 2003 by Remote Sensing and GIS Methods. Int. J. Geogr. Inf. Sci. 2009, 23, 1371-1388.

43. Xie, Y.; Fang, C.; Lin, G.; Gong, H.; Qiao, B. Tempo-spatial patterns of land use changes and urban development in globalizing China: A study of Beijing. Sensors 2007, 7, 2881-2906.

44. Yue, W.; Liu, Y.; Fan, P. Polycentric urban development: The case of Hangzhou. Environ. Plan. A 2010, 42, 563-577.

45. Lu, S.; Guan, X.; He, C.; Zhang, J. Spatio-temporal patterns and policy implications of urban land expansion in metropolitan areas. Sustainability 2014, 6, 4723-4748.

46. SPLRA (Shanghai Planning and Land Resources Administration). The Evaluation Report of Shanghai Urban Master Plan Implementation; Shanghai Planning and Land Resources Administration: Shanghai, China, 2014. (In Chinese)

47. Cheng, J.; Masser, I. Modeling urban growth patterns: A multiscale perspective. Environ. Plan. A 2003, 35, 679-704

48. Cheng, J.; Masser, I. Urban growth pattern modeling: A case study of Wuhan City, PR China. Landsc. Urban Plan. 2003, 62, 199-217.

49. Li, X.; Yeh, A.G.O. Modeling sustainable urban development by the integration of constrained cellular automata and GIS. Int. J. Geogr. Inf. Sci. 2000, 14, 131-152.

50. Fotheringham, A.S.; Brunsdon, C.; Charlton, M.E. Geographically Weighted Regression: The Analysis of Spatially Varying Relationships; John Wiley Sons Ltd.: Chichester, UK, 2002.

51. Shafizadeh-Moghadam, H.; Helbich, M. Spatiotemporal variability of urban growth factors: A global and local perspective on the megacity of Mumbai. Int. J. Appl. Earth Observ. Geoinf. 2015, 35, 187-198.

52. Cravo, T.A.; Resende, G.M. Economic growth is Brazil: A spatial filtering approach. Ann. Reg. Sci. 2013, 50, 555-575.

53. Wei, Y.H.D.; Lin, G.S.C. China's restless urban landscapes 2: Socialist state, globalization, and urban change. Environ. Plan. A 2002, 34, 1721-1724.

54. Tian, L.; Ma, W. Government intervention in city development of China: A tool of land supply. Land Use Policy 2009, 26, 599-609.

(C) 2014 by the authors; licensee MDPI, Basel, Switzerland. This article is an open access article distributed under the terms and conditions of the Creative Commons Attribution license (http://creativecommons.org/licenses/by/4.0/). 